\title{
Local, electronic and surface structure of multi-component Fe-doped $\mathrm{CdTe}(\mathrm{S})$ systems
}

\author{
N. Bundaleski ${ }^{\mathrm{a}, \mathrm{b}}$, I. Radisavljević ${ }^{\mathrm{a}, *}$, \\ N. Ivanovića , Z. Rakočevića $^{\mathrm{a}}$ M. Medić Ilić ${ }^{\mathrm{a}}$, N. Romčevićc ${ }^{\mathrm{c}}$, O.M.N.D. Teodoro ${ }^{\mathrm{b}}$
}

${ }^{a}$ University of Belgrade-Vinča Institute of Nuclear Sciences, P.O. Box 522, 11001 Belgrade, Serbia

${ }^{\mathrm{b}}$ Universidade Nova de Lisboa-Faculdade de Ciências e Tecnologia, Quinta da Torre 2829-516

Caparica, Portugal

${ }^{c}$ University of Belgrade-Institute of Physics, Pregrevica 118, 11000 Belgrade, Serbia

Corresponding author: Tel.: +381 113408 254; Fax: +381 113440100 .

E-mail address: iva@vin.bg.ac.rs (I. Radisavljević)

\begin{abstract}
Local structural and electronic properties around $\mathrm{Fe}$ in multi-component $\mathrm{Cd}_{0.99} \mathrm{Fe}_{0.01} \mathrm{Te}_{0.97} \mathrm{~S}_{0.03}$ system were studied by means of X-ray absorption fine structure (XAFS). Composition of nonpolar (110) surfaces of $\mathrm{Cd}_{0.97} \mathrm{Fe}_{0.03} \mathrm{Te}$ and $\mathrm{Cd}_{0.99} \mathrm{Fe}_{0.01} \mathrm{Te}_{0.97} \mathrm{~S}_{0.03}$ systems and mechanism of their oxidation in ambient conditions were studied by Atomic Force Microscopy (AFM) and X-ray Photoelectron Spectroscopy (XPS). It has been found that Fe preferentially substitutes Cd, but due to much smaller covalent radius and preferences for paring with $\mathrm{S}$, it causes local distortion of the host CdTe lattice. The distortion is confined to the Fe-immediate surrounding and the second and third coordination shell atoms are (inside experimental uncertainties) placed at distances expected in CdTe. Although local structure around Fe is well defined in the bulk of both samples, their nearsurface region is completely depleted from $\mathrm{Fe}$, and in case of $\mathrm{Cd}_{0.99} \mathrm{Fe}_{0.01} \mathrm{Te}_{0.97} \mathrm{~S}_{0.03}$ somewhat enriched in S. Special attention is, therefore, paid to characterization of the near-surface region and evaluation of its composition and structure. To that end we have introduced a general standard-free algorithm for XPS data analysis of the two-layer surface structure (bulk, oxide layer, and the impurity layer). Results of the in-depth composition analysis revealed that despite different bulk composition and impurity layer thickness, underneath the topmost impurity layer lays approximately one monolayer of $\mathrm{CdTeO}_{3}$ which passivates the surface.
\end{abstract}

Keywords: II-VI semiconductors; iron impurity; oxidation; XAS; XPS 


\section{Introduction}

Iron-doped II-VI semiconductors exhibit advantageous spectroscopic characteristics which make them particularly suitable for mid-IR laser fabrication [1-3]. These materials are also prospective for spintronics applications [4,5] and can serve as convenient model systems for studying mechanisms of magnetic interaction [6], effects related to charge order [7] and atomic correlations $[8,9]$. In multi-component II-VI semiconductors replacement of group II cation and/or group VI anion offers possibility to simultaneously adjust the band gap and lattice constant [10] and allows for independent engineering of the Fe absorption and photoluminescence bands' positions by varying composition, type and amount of the substitute ions [11]. In addition to spectroscopic characteristics, ion substitution can also alter physical properties of the material [12]. Presence of different types of anions changes the symmetry of $\mathrm{Fe}$ ion environment and affects the electronic structure of the valence band, which can have strong impact on the magnetic properties. Depending on composition and configuration of its immediate surroundings, the ground state of $\mathrm{Fe}^{2+}$ ion can switch from nonmagnetic singlet in $\mathrm{Cd}_{1-\mathrm{x}} \mathrm{Fe}_{\mathrm{x}} \mathrm{Te}$ to magnetically active doublet in $\mathrm{Cd}_{1-\mathrm{x}} \mathrm{Fe}_{\mathrm{x}} \mathrm{Te}_{1-\mathrm{y}} \mathrm{Se}_{\mathrm{y}}$ [13]. Another demonstration of the effect of anion substitution on the material properties is found in new family of Fe-based superconductors, where partial substitution of Te by $\mathrm{S}$ can induce appearance of superconductivity in otherwise non superconductive FeTe $[14,15]$. The discovery that superconductivity can be induced upon exposure of the FeTe and $\mathrm{FeTe}_{1-\mathrm{x}} \mathrm{S}_{\mathrm{x}}$ to air [16] triggered research towards clarifying the influence of oxygen. The role of oxygen is also crucial for understanding the activation process of $\mathrm{CdTe} / \mathrm{CdS}$ interfaces in photovoltaic devices. Oxygen presence during the device fabrication improves morphology and structure and plays a critical role in passivation of deep gap states and hardening against the intriguing processes of the Te interdiffusion and S outer - diffusion [17]. The efficiency and spatial uniformity of devices is interpreted as due to the oxidation of grain boundaries, but the structure and composition of the surface oxide, which can penetrate deep below the CdTe surface, is highly debatable $[17,18]$. The oxidation process of the $\mathrm{CdTe}(011)$ surface and the oxidation kinetics are known to be influenced by the amount and type of surface defects [19]. Oxidation conditions at the surfaces of multicomponent CdTe-based systems are strongly affected by the type and concentration of dopants [20]. Detailed characterization of the semiconductor surfaces and their oxidation processes are therefore crucial for understanding the electronic consequences of the surface states on the functionality of the devices [21, 22]. 
In this paper, local and electronic structure around $\mathrm{Fe}$ in multi-component $\mathrm{Cd}_{0.99} \mathrm{Fe}_{0.01} \mathrm{Te}_{0.97} \mathrm{~S}_{0.03}$ system is studied by means of X-ray absorption fine structure (XAFS). Composition and mechanism of the $\mathrm{Cd}_{0.97} \mathrm{Fe}_{0.03} \mathrm{Te}$ and $\mathrm{Cd}_{0.99} \mathrm{Fe}_{0.01} \mathrm{Te}_{0.97} \mathrm{~S}_{0.03}(011)$ surface oxidation in ambient conditions were studied by Atomic Force Microscopy (AFM) and X-ray Photoelectron Spectroscopy (XPS). XPS is a powerful tool for surface characterization, which enables to determine quantitative surface composition and to indentify bonds. These two sets of data are obtained independently from the intensities and the exact positions of the photoelectron lines. In standard applications, the composition analysis is performed by means of Atomic Sensitivity Factors (ASFs) [23], an approach which implicitly assumes uniformity of the analyzed system. A semiconductor surface covered with a thin oxide layer is typical example of the system for which the above approximation is not valid. In spite of that, composition analysis based on ASFs (relying on rather loose assumption that it would yield 'average' surface composition) is still widely exploited. Here, we propose a general standard-free algorithm for XPS spectra analysis, which can be applied to estimate composition and thickness of the two-layer surface structure (bulk, oxide layer and the impurity layer). The approach is based on the earlier contributions of different authors $[24,25]$, and takes into account in-depth non-uniformity of the analyzed sample.

\section{Experimental details}

The crystalline samples $\mathrm{Cd}_{0.99} \mathrm{Fe}_{0.01} \mathrm{Te}_{0.97} \mathrm{~S}_{0.03}$ (CFTS) and $\mathrm{Cd}_{0.97} \mathrm{Fe}_{0.03} \mathrm{Te}$ (CFT) were grown by the Bridgman method at the Institute of Physics of the Polish Academy of Science (Warszawa, Poland). X-ray absorption fine structure (XAFS) experiments on Fe K-edge in CFTS sample were performed in fluorescence mode at beamline C1 of HASYLAB at Deutsches ElektronenSynchrotron DESY. The synchrotron radiation source was operating at $4.44 \mathrm{GeV}$, with maximal stored current $\mathrm{I}_{\max }=140 \mathrm{~mA}$. Samples were oriented at $45^{\circ}$ with respect to the incident beam and a 7-segment Ge-detector was used to collect the spectra at T=10 K and $293 \mathrm{~K}$. Multiple scans were taken to improve signal-to-noise ratio. Data processing and analysis were performed using ATHENA and ARTEMIS packages [26], according to the standard procedure described elsewhere [27]. In the fitting procedure following parameters were varied: the mean distance of the $j^{\text {th }}$ shell $\left(R_{j}\right)$, the number of atoms in the $j^{t h}$ shell $\left(N_{j}\right)$, the mean-squared displacement of atoms in the $j^{\text {th }}$ shell $\left(\sigma_{j}^{2}\right)$, and the single edge shift correction $\left(\Delta E_{0}\right)$.

Multimode quadrex SPM with Nanoscope IIIe controller (Veeco Instruments, Inc.) operated under ambient conditions is used to acquire surface topography and phase images of CFTS sample. 
Standard AFM tapping mode with a commercial NanoScience-Team Nanotec GmbH SNC (Solid Nitride Cone) AFM probe (with the tip radius smaller than $10 \mathrm{~nm}$ ) has been employed. The saturated surface roughness is estimated with the help of WSxM application software [28], as the average value of several $(2 \times 2) \mu \mathrm{m}$ AFM images taken from different surface points.

XPS measurements were performed on a VSW XPS system, using the non-monochromatic $\mathrm{Mg} \mathrm{\textrm {K } _ { \alpha }}$ line with photon energy of $1253.6 \mathrm{eV}$ and the Class 100 energy analyzer, being a part of an experimental setup assembled for surface characterization [29]. Samples were introduced into the vacuum chamber with the base pressure $2-3 \cdot 10^{-9}$ mbar and measurements were performed on asreceived samples without any previous chemical treatment. Sputter-cleaning was performed using $3 \mathrm{keV} \mathrm{Ar}^{+}$ion beam. The beam impinging the surface at $45^{\circ}$ was rastered over the whole sample area. Low ion fluencies were used to minimize sputtering of the oxidation layer and to avoid modification of the surface composition. In order to determine optimal sputter-cleaning conditions a set of test XPS measurements were performed on the CFT sample. The first two sets were performed the same day on as-received sample and after applying 10 sputtering cycles. The third set, performed the day after using additional 10 sputtering cycles (20 cycles in total), is adopted as optimal, as explained in more details in Section 4.3. Therefore, both samples were cleaned by 20 sputtering cycles, corresponding to overall fluence of about $2 \cdot 10^{15} \mathrm{~cm}^{-2}$. The thickness of the organic impurities removed with this fluence is $1.5-2$ monolayers, as estimated using the SRIM code [30]. The energy axis was calibrated using the $\mathrm{Ag} 3 \mathrm{~d}_{5 / 2}$ XPS line position (368.22 eV [31]) of sputter-cleaned Ag (110) monocrystal and the $\mathrm{Au} 4 \mathrm{f}_{7 / 2}$ XPS line position (83.96 eV [31]) of sputter-cleaned polycrystalline Au sample. The survey spectra were taken in FAT 44 mode (analyzer pass energy $44 \mathrm{eV}$ ), with the energy step $0.5 \mathrm{eV}$, and acquisition time $0.5 \mathrm{~s} /$ channel. Detailed spectra of characteristic XPS lines were taken in FAT 22 mode (analyzer pass energy 22 $\mathrm{eV}$ ) with the energy step $0.1 \mathrm{eV}$ and the acquisition time $4 \mathrm{~s} /$ channel. The energy intervals around $\mathrm{S}$ and Fe 2p XPS lines were scanned with much longer acquisition time (16 and 20 s/channel, respectively). Due to the sample charging [8], the relevant chemical information is extracted from the relative positions of XPS lines, rather than from the absolute line positions (no charge correction of the energy axis is performed). The charging-effect in investigated samples is closely related to the amount of carbon impurities at their surfaces. Modest sputter-cleaning treatment leaves considerable amount of adventitious carbon (i.e. saturated hydrocarbons) which increases surface conductivity and thereby reduces the samples' charging. The influence of contamination on the photoelectron signals is accounted for in the procedure of quantitative analysis. 


\section{XPS composition quantification of the in-depth non-uniform surfaces}

Standard XPS composition analysis using atomic sensitivity factors (ASFs) [23] is valid only if the sample consists of a single phase. For non-uniform samples, more complicated strategy based on the first principles has to be applied. Here we focus on the case when the sample is only in-depth non-uniform, which is frequently encountered in practice and has already been considered by many authors since 1970's [24, 25, 32-36]. The XPS composition analysis is based on the intensities of characteristic photoelectron lines. The line intensity is directly proportional to the atomic concentration in the analyzing volume, which is defined by the acceptance area of the spectrometer and the information depth of the technique. For given kinetic energy of the photoelectrons $E_{i}$, fraction of the XPS line intensity $d I\left(E_{i}, z\right)$ originating from a layer of thickness $d z$ at depth $z$ (obtained after background subtraction), can be written in the following form [23]:

$$
d I\left(E_{i}, z\right)=J_{x} \cdot n_{i}(z) \cdot \frac{\sigma_{i}}{4 \pi}\left[1+\frac{\beta_{i}}{4}\left(1-3 \cos ^{2} \psi\right)\right] \cdot T\left(E_{i}\right) \cdot \varphi_{i}(z) d z,(1)
$$

where $J_{x}-$ the flux of $\mathrm{X}$-ray photons, $n_{i}(z)$ - the atomic concentration of element $i, \sigma_{i}-$ the isotropic cross section for the $i^{\text {th }}$ photoelectron emission. The term in square bracket represents non-isotropic part of the cross section with asymmetry parameter $\beta$, and angle between the incident $\mathrm{X}$ - ray beam and the trajectory of detected photoelectrons $\psi \cdot T\left(E_{i}\right)$ is transmission function of the XPS spectrometer and $\varphi_{i}(z)$ is the emission depth distribution function (EDDF) of electrons which are leaving the sample without energy loss. Transmission function is product of acceptance solid angle of the spectrometer $(\Delta \Omega)$, acceptance area of the spectrometer $(A)$ and detection efficiency $(D)$ :

$$
T\left(E_{i}\right)=\Delta \Omega \cdot A \cdot D,(2)
$$

Since the XPS spectrometers work in the fixed analyzer transmission mode, the transmission function can be conveniently written in the form:

$$
T\left(E_{i}\right)=\frac{k}{E_{i}^{n}},(3)
$$

where $k$ - constant, $E_{i}$ - kinetic energy of photoelectrons and $0.5<n<1$ [37]. In the XPS setup used in this work $n=1$ and thus we will proceed with the expression $T\left(E_{i}\right)=k / E_{i}$. In Eq. (1), EDDF is normalized according to condition $\varphi_{i}(z=0)=1$ [38], and represents the probability of zero-loss photoelectron emission. Given that most XPS setups make use of so-called magic angle $\left(\psi \approx 54.7^{\circ}\right)$ for which the anisotropy term becomes 1 , Eq. (1) can be rewritten as:

$$
d I\left(E_{i}, z\right)=J_{x} \cdot N(z) \cdot x_{i}(z) \cdot \frac{\sigma}{4 \pi} \cdot \frac{k}{E_{i}} \cdot \varphi_{i}(z) d z,(4)
$$


where the atomic concentration $n_{i}(z)$ is expressed as a product of total atomic concentration $N(z)$ and relative atomic concentration $x_{i}(z)$ of element $i$. Note that XPS is not able to provide absolute atomic concentrations since the flux of $\mathrm{X}$-ray photons $\left(J_{x}\right)$ is not measured in typical experiments. When elastic scattering of photoelectrons is neglected, $\varphi_{i}(z) \approx \exp \left(-z / \lambda_{i}\right)$, where $\lambda_{i}$ represents inelastic mean free path (IMFP) which depends on both electron energy and the matrix [39]. In more advanced approach, EDDF is either obtained from Monte Carlo simulations, or by using socalled transport approximation. Analysis of in-depth non-uniform samples is usually based on the exponential approximation of $\operatorname{EDDF}: \varphi_{i}(z) \approx \exp \left(-z / L_{i}\right)$. The parameter $L_{i}$ represents effective attenuation length (EAL) [39, 40], and can be calculated for any given photoelectron line and material of interest using appropriate NIST database [41]. Integration of Eq. (4) over the total thickness yields the total intensity of the $i^{\text {th }}$ photoelectron line:

$$
I\left(E_{i}\right)=J_{x} \cdot \frac{\sigma_{i}}{4 \pi} \cdot \frac{k}{E_{i}} \cdot \int_{0}^{\infty} N(z) \cdot x_{i}(z) \cdot e^{-\frac{z}{L_{i}}} d z .(5)
$$

In special case of uniform, single-phased sample ( $N, x_{i}=$ const.) which consists of $m$ elements, we can write the expression for the normalized line intensities (equivalent to the expression used in ASFs-based composition analysis):

$$
x_{i}=\frac{\frac{I_{i} \cdot E_{i}}{\sigma_{i}}}{\sum_{j=1}^{m}\left[\frac{I_{j} \cdot E_{j}}{\sigma_{j}} \cdot \frac{L_{Q j}}{L_{Q i}}\right]},(6)
$$

where the total atomic concentration $(N)$ and the X-ray flux $\left(J_{x}\right)$ will be canceled. Quantities $L_{Q j}$ result from numerical integration of $\operatorname{EDDF}$ in the range $(0, \infty)$ and represent quantitative attenuation lengths. Although $L_{Q j}$ (as well as the corresponding EALs) strongly depend on the matrix, their ratio is matrix independent to a very good approximation [42]. In a multiphase sample, however, the total atomic concentrations $N$ (addressed to each phase) will not be canceled and the ratio between EALs attributed to different phases (which are now used instead of quantitative attenuation lengths) may be strongly matrix dependent. When material is non-uniform, the question of relative amounts of different elements is of secondary importance. What one would actually want to know is: (a) which chemical phases are present in the analyzed volume, (b) what their amount is, and (c) how are they distributed in the sample. It is rather hard to address all these issues using a single experimental technique. Nevertheless, XPS possesses unique features which enable to tackle this problem. Let us assume a system which comprises phase ' $b$ ' covered with layer ' $o$ ' with thickness $d_{o}$. If the same element ' $i$ ' is present in both phases (with respective relative concentrations $x_{i}^{b}$ and $x_{i}^{o}$ and atomic concentrations $N_{b}$ and $N_{o}$ ) associated photoelectron line will have two contributions. From Eq. (1), the relative intensities of the two contributions are: 


$$
\begin{gathered}
I_{i}^{o}=J_{x} \cdot N_{o} \cdot x_{i}^{o} \cdot \frac{\sigma_{i}}{4 \pi} \cdot \frac{k}{E_{i}} \cdot L_{i}^{o} \cdot\left(1-e^{-\frac{d_{o}}{L_{i}^{o}}}\right), \\
I_{i}^{b}=J_{x} \cdot N_{b} \cdot x_{i}^{b} \cdot \frac{\sigma_{i}}{4 \pi} \cdot \frac{k}{E_{i}} \cdot L_{i}^{b} \cdot e^{-\frac{d_{o}}{L_{i}^{o}}},(8)
\end{gathered}
$$

From the ratio of the intensities given by Eq. (7) and Eq. (8):

$$
\frac{I_{i}^{o}}{I_{i}^{b}}=\frac{N_{o} x_{i}^{o} L_{i}^{o}}{N_{b} x_{i}^{b} L_{i}^{b}}\left(e^{\frac{d_{o}}{L_{i}^{o}}}-1\right),
$$

the thickness of the layer $o$ can be expressed as:

$$
d_{o}=L_{i}^{o} \cdot \ln \left(\frac{N_{b} x_{i}^{b} L_{i}^{b}}{N_{o} x_{i}^{o} L_{i}^{o}} \frac{I_{i}^{o}}{I_{i}^{b}}+1\right)
$$

This approach, equivalent to the one originally introduced by Fadley and co-workers [24] (the exception is that here EALs are used instead of IMFPs), is readily employed for analysis of singlelayer structures, such as bulk metals covered with thin oxide layers [32-36]. If, however, the element ' $i$ ' is present only in a surface layer ' $O$ ', the line intensity is:

$$
I_{i}\left(d_{o}\right)=I_{i 0} \cdot\left(1-e^{-\frac{d_{o}}{L_{i}^{o}}}\right),
$$

where $L_{i}^{o}$ is EAL of the line ' $i$ ' in the layer ' $o$ ' and

$$
I_{i 0}=J_{x} \cdot N_{o} \cdot x_{i}^{o} \cdot \frac{\sigma_{i}}{4 \pi} \cdot \frac{k}{E_{i}} \cdot L_{i}^{o}
$$

represents intensity of the line in case of uniform sample $(\mathrm{d} \rightarrow \infty)$. Finally, if the element ' $i$ ' is present only in the bulk, the line intensity is:

$$
I_{i}=I_{i 0} \cdot e^{-\frac{d_{o}}{L_{i}^{o}}}
$$

In many cases, the sample surface is also covered with a thin layer of organic impurities.

Equivalent approach for quantification of the two-layer structure (illustrated in Fig. 1), yields a set of transcendent equations, whose solution is hindered by the fact that impurity layer typically comprises a mixture of different organic compounds (and it is therefore difficult to be precisely defined).

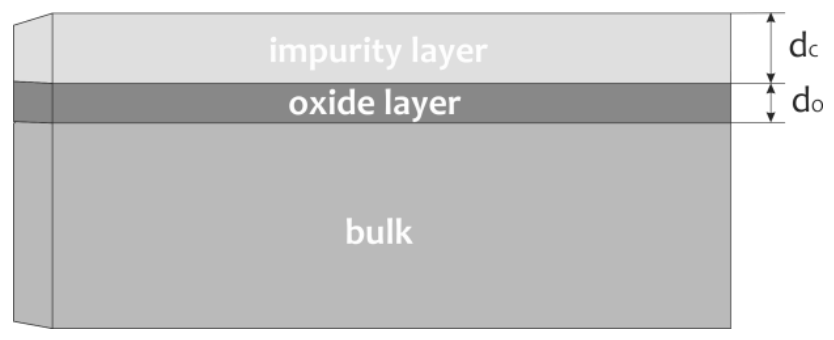

Fig. 1. Surface structure of the bulk sample covered with oxide layer $\left(d_{o}\right)$ and impurity layer $\left(d_{c}\right)$. 
The first step in the composition analysis of in-depth non-uniform samples is to perform fitting of photoelectron lines in order to identify atomic bonds and corresponding chemical phases. To that end, the sample is divided into uniform regions (bulk $-b$, oxide $-o$, impurity layer $-c$ ) as shown in Fig. 1. Basic assumption is that each region is uniform and comprises a single phase. If the same element is present in more than one region, associated photoelectron line will be composed of several contributions. The contribution of $i^{\text {th }}$ photoelectron line originating from the $m^{\text {th }}$ region is denoted with " $i$ ". . Each line contribution $\left(i^{m}\right)$ can be assigned an effective intensity $\left(S_{i}^{m}\right)$ :

$$
S_{i}^{m}=\frac{I_{i}^{m} \cdot E_{i}}{\sigma_{i} \cdot L_{i}^{m}}
$$

where $I_{i}^{m}$ represents experimentally measured intensity and $L_{i}^{m}$ is the EAL of contribution $i^{m}$, which is readily calculated from the experimental data.

The effective intensities can also be expressed as a function of relative and total atomic concentrations $\left(x_{i}, N_{m}\right)$ and thickness of the oxide $\left(d_{o}\right)$ and impurity layer $\left(d_{c}\right)$. For each line/line contribution which originates from the contamination layer and using Eq. (11) and Eq. (12), the following expression can be written:

$$
S_{i}^{c}=A \cdot N_{c} \cdot x_{i}^{c} \cdot\left(1-e^{-\frac{d_{c}}{L_{i}^{c}}}\right), i=1 \ldots i_{c},(15)
$$

where $A=J_{x} \cdot k /(4 \pi)$ represents proportionality constant. The effective intensity of the line/line contribution from the oxide layer $o$, located underneath the contamination layer, can be obtained via Eq. (11) - (13):

$$
S_{i}^{o}=A \cdot N_{o} \cdot x_{i}^{o} \cdot\left(1-e^{-\frac{d_{o}}{L_{i}^{o}}}\right) \cdot e^{-\frac{d_{c}}{L_{i}^{c}}}, i=1 \ldots i_{o}
$$

Finally, the effective intensity of the line/line contribution which originates from the bulk is:

$$
S_{i}^{b}=A \cdot N_{b} \cdot x_{i}^{b} \cdot e^{-\frac{d_{o}}{L_{i}^{o}}} \cdot e^{-\frac{d_{c}}{L_{i}^{c}}}, i=1 \ldots i_{b} \cdot(17)
$$

Effective intensities derived from the experimental data using Eq. (14) and calculated using Eqs. (15) - (17) can only be compared after their normalization:

$$
S_{i n}^{u}=\frac{S_{i}^{u}}{\sum_{v}\left(\sum_{w} S_{w}^{v}\right)}
$$

where $S_{w}{ }^{v}$ represents the effective intensity of the line contribution $w$ originating from the region $v$. Note that normalization eliminates the unknown constant A from Eqs. (15) - (17).

The quantity:

$$
x_{i}^{*}=\Sigma_{\mathrm{u}}\left(S_{i n}{ }^{u}\right),
$$


assigned to the $i^{\text {th }}$ line/line-component is denoted as apparent relative concentration of element " $i$ ". Note that in the case of uniform sample quantities $x_{i}{ }^{*}$ correspond to the actual relative concentrations $x_{i}$ given by Eq. (6).

The ultimate goal of the two-layer model is to find the structure for which the experimentallyderived and calculated apparent relative concentrations coincide within statistical uncertainty of the measurement. To that end, the analysis proceeds in the following iterative-like manner:

1) The composition of each segment $(m=b, o, c)$ is proposed according to the bond identification.

2) Thickness of the oxide layer $\left(d_{o}\right)$ is calculated using Eq. (10), from the relative intensities of the two well-resolved bulk/oxide contributions of a chosen photoelectron line.

3) Effective intensities of each line/line-contribution are derived from experimental data via Eq. (14) and subsequently normalized to obtain apparent relative concentrations (see Eq. (18) and Eq. (19).

4) Apparent relative concentrations are at the same time expressed as a function of the impurity layer thickness $\left(d_{c}\right)$ using Eqs. (15) - (19).

5) The final step is to find the $d_{c}$ value for which experimentally-derived (step 3 ) and calculated apparent relative concentrations (step 4) match within statistical uncertainty of the measurement. The composition of each segment is modified and the whole procedure is repeated until the structure compatible with the measurements is estimated.

\section{Results and discussion}

\subsection{XAFS}

Fourier transforms (FT) of the $k^{2}$-weighted EXAFS function $k^{2} \chi(k)$ extracted from the CFTS sample Fe K-absorption edge data taken at $10 \mathrm{~K}$ and $293 \mathrm{~K}$ (RT) are presented in Fig. 2a and Fig. 2b. The corresponding XANES spectra are presented in Fig. 2c and Fig. 2d, with the k-space EXAFS oscillations given in insets. The fitting results are summarized in Table 1. Amplitude reduction factor was kept fixed $\left(S_{0}^{2}=0.7\right)$ and the fit quality factor ( $\mathrm{R}$-factor) was better than $2 \%$. 

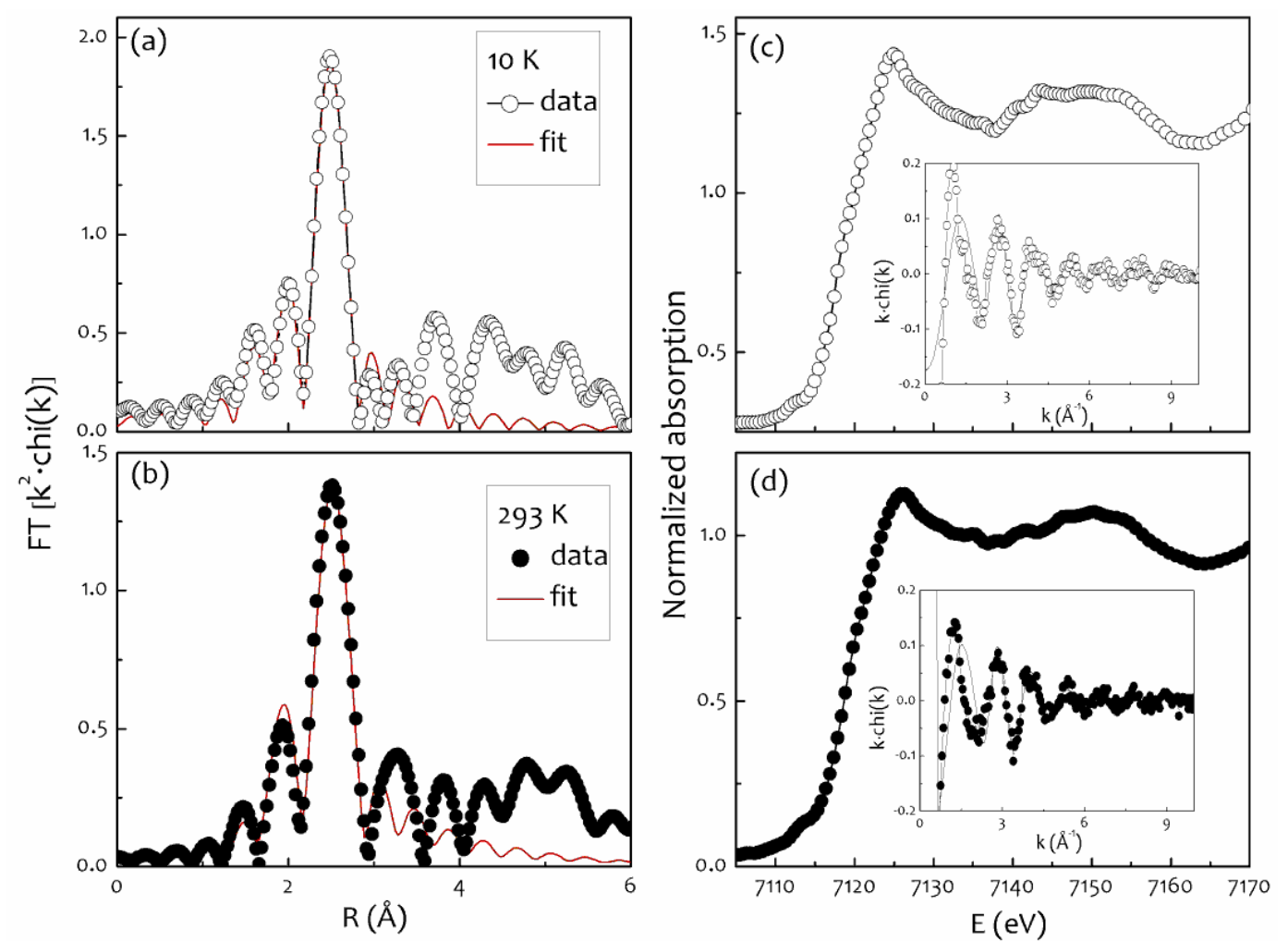

Fig. 2. Fourier transforms (FT) of the $k^{2}$-weighted EXAFS function $k^{2} \chi(k)$ extracted from the Fe K-absorption edge data taken at (a) T=10 K and (b) T=293 K (RT) of the CFTS sample. The experimental data are represented with circles, and the best fits with lines. The Fe $\mathrm{K}$-absorption edge XANES spectra of CFTS sample taken at (c) T=10 K and (d) T=293 K (RT). The k-space EXAFS oscillations are shown in insets.

\section{Table 1}

Results of the Fe K-edge EXAFS data analysis of CFTS sample collected at $10 \mathrm{~K}$ : interatomic distances $(r)$, Debye-Waller factors $\left(\sigma^{2}\right)$, coordination numbers $(n)$ and phase shift correction $\left(\mathrm{E}_{0}\right)$. Experimental uncertainties of the parameters evaluated in the fit are given in parenthesis (otherwise they are kept fixed). Room temperature (RT) data obtained for the first coordination shell $\left(\mathrm{Fe}-\mathrm{Te}_{\mathrm{I}}\right)$ are given in italic.

\begin{tabular}{lllll}
\hline & $r(\AA)$ & $\sigma^{2}\left(\AA^{2}\right)$ & $n$ & $\mathrm{E}_{0}(\mathrm{eV})$ \\
\hline $\mathrm{Fe}-\mathrm{Te}_{\mathrm{I}}$ & $2.665(6)$ & $0.0015(6)$ & $3.2(2)$ & $-2.7(8)$ \\
& $2.65(1)$ & $0.004(1)$ & $3.5(5)$ & $-2.4(7)$ \\
\hline $\mathrm{Fe}-\mathrm{S}_{\mathrm{I}}$ & $2.35(3)$ & 0.0015 & 0.8 & -2.7 \\
\hline $\mathrm{Fe}-\mathrm{Cd}_{\mathrm{II}}$ & $4.55(4)$ & $0.013(3)$ & 12 & $3(2)$ \\
\hline $\mathrm{Fe}-\mathrm{Te}_{\mathrm{III}}$ & $5.33(5)$ & $0.019(9)$ & 12 & -2.7 \\
\hline
\end{tabular}


In the analysis of the experimental Fe K-edge EXAFS spectra, theoretical model of cubic zincblende CdTe structure is used, where one type of atoms is tetrahedrally coordinated with atoms of different kind. Iron is found to substitute $\mathrm{Cd}$ at regular lattice sites and its first coordination tetrahedron is at low temperatures $(\mathrm{T}=10 \mathrm{~K})$ composed of both $\mathrm{Te}$ and $\mathrm{S}$, with bimodal distribution of nearest neighbor $(\mathrm{NN}) \mathrm{Fe}-\mathrm{Te}$ and $\mathrm{Fe}-\mathrm{S}$ distances (see Table 1). The obtained $\mathrm{Fe}-\mathrm{Te}$ and $\mathrm{Fe}-\mathrm{S}$ distances are both smaller than the $\mathrm{Cd}-\mathrm{Te}$, but perfectly match the sum of the corresponding tetrahedral covalent radii [10]. The fact that the $\mathrm{Fe}-\mathrm{S}$ bonds are favorable even at such low atomic concentrations $(\mathrm{x}=0.01 ; \mathrm{y}=0.03)$ implies that Fe has a preference for paring with $\mathrm{S}$. The local bimodal distribution of $\mathrm{Fe}$-chalcogen distances has also been observed in other similar multicomponent systems [8]. The distortion of the host lattice is confined to the Fe-immediate surrounding and the second and third coordination shells are inside experimental uncertainty, placed at distances expected in $\mathrm{CdTe}$ [10]. At room temperature, large thermal distortions hinder the exact determination of the local structure beyond the first Fe-Te coordination shell. Uncertainties are much larger due to large thermal distortions. Nevertheless, the first coordination shell distance agrees well with that obtained at low temperature (see Table 1) and the local structure around $\mathrm{Fe}$ remains nearly the same, as can be deduced from the comparison of the $\mathrm{Fe} \mathrm{K}$-edge XANES spectra taken at T=10 and $293 \mathrm{~K}$ (see Fig. 2c and Fig. 2d). The overall shape of the XANES spectra is almost exactly alike at the two temperatures. Also, similar slope of the rising edge implies that there is no substantial change of Fe valence state between the two temperatures.

\section{2. $A F M$}

AFM images of the CFTS sample showing 2D phase and 3D surface topography are given in Fig. 3. AFM analysis reveals that the surface of the sample is rather rough (see Fig. 3b), with the root mean square roughness RMS=6.1 nm and the maximum peak to valley height difference $60.8 \mathrm{~nm}$. At the same time, the phase image (see Fig. 3a) reveals that the first monolayer of the sample is laterally uniform in composition. 

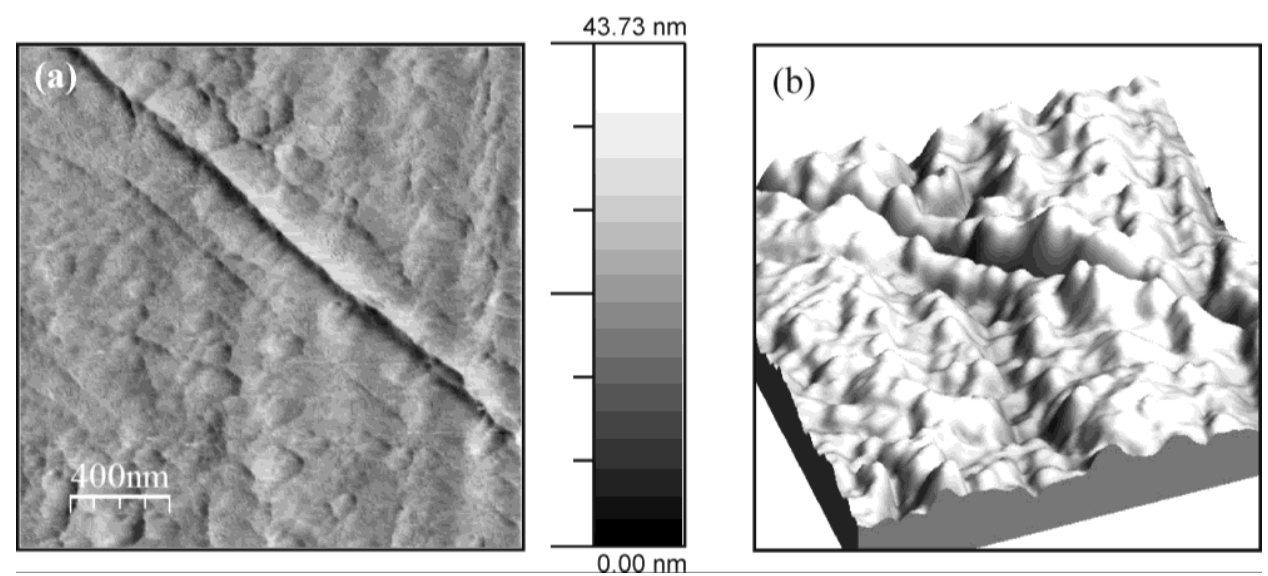

Fig. 3. AFM images of CFTS sample showing (a) 2D phase and (b) 3D surface topography.

\subsection{XPS}

Survey XPS spectra of both investigated samples are presented in Fig. 4. Typical Cd and Te photoelectron and Auger lines, as well as the characteristic $\mathrm{O}$ and $\mathrm{C}$ photoelectron lines are clearly distinguished. Iron is not detected, although its concentration in the investigated samples $(0.5-1.5$ at. \%) exceeds the sensitivity limit of the performed XPS measurements. Iron surface depletion has already been observed in other Fe-doped II-VI systems (e.g. $\mathrm{Cd}_{1-\mathrm{x}} \mathrm{Fe}_{\mathrm{x}} \mathrm{Te}(\mathrm{x} \leq 0.07)$ [43], $\mathrm{Zn}_{1-}$ ${ }_{x} \mathrm{Fe}_{\mathrm{x}} \mathrm{Te}_{1-\mathrm{y}} \mathrm{Se}_{\mathrm{y}}$ [8], $\mathrm{Cd}_{1-\mathrm{x}} \mathrm{Fe}_{\mathrm{x}} \mathrm{Te}_{1-\mathrm{y}} \mathrm{Se}_{\mathrm{y}}$ [44], which implies that it could be their intrisic characteristic. The main S 2p XPS line was observed at the surface of the CFTS sample after careful scanning of the corresponding energy interval (160-170 eV).

As can be seen from Fig. 4a, C and $\mathrm{O}$ signals were drastically reduced after the first ten sputtering cycles. Increase of $\mathrm{Te}$ and $\mathrm{Cd}$ lines and change in their background indicates that sputter-cleaning removes upper layers of the surface contaminants. From this perspective and having in mind the AFM phase imaging, it was obvious that the surfaces of as-received samples had originally been uniformly covered with organic impurities. Upon applying additional ten sputtering cycles, $\mathrm{C}$ and $\mathrm{O}$ contents are further reduced. At the same time, the shape of the Te- $3 \mathrm{~d}$ line is being modified, as can be seen from the inset of Fig. 4a. This line consists of two contributions (corresponding to two different tellurium-containing phases) whose intensities increase after the first ten sputtering cycles. The intensity of the contribution at lower binding energy continues to increase after additional ten sputtering cycles, while the contribution at higher binding energy saturates in intensity (see Fig. 4a-inset). This was a clear indication that in the course of final sputtering cycle ion bombardment begins to contribute to the etching of one tellurium-containing phase. To reduce 
uncontrolled changes of the surface composition (which might result from preferential sputtering, ion beam mixing and different post- bombardment processes), no further sputter-cleaning was performed. The 20 sputtering cycles, adopted as the optimal sputter-cleaning condition, was subsequently applied to treat CFTS sample (see Fig. 4b). Considerable amount of adventitious carbon still present at the samples' surfaces partially screens the signal from the underneath layers, but at the same time it helps to reduce the charging, as mentioned earlier. Attenuation of the signal through the impurity layer is accounted for in the procedure of quantitative analysis given at the end of this Section.

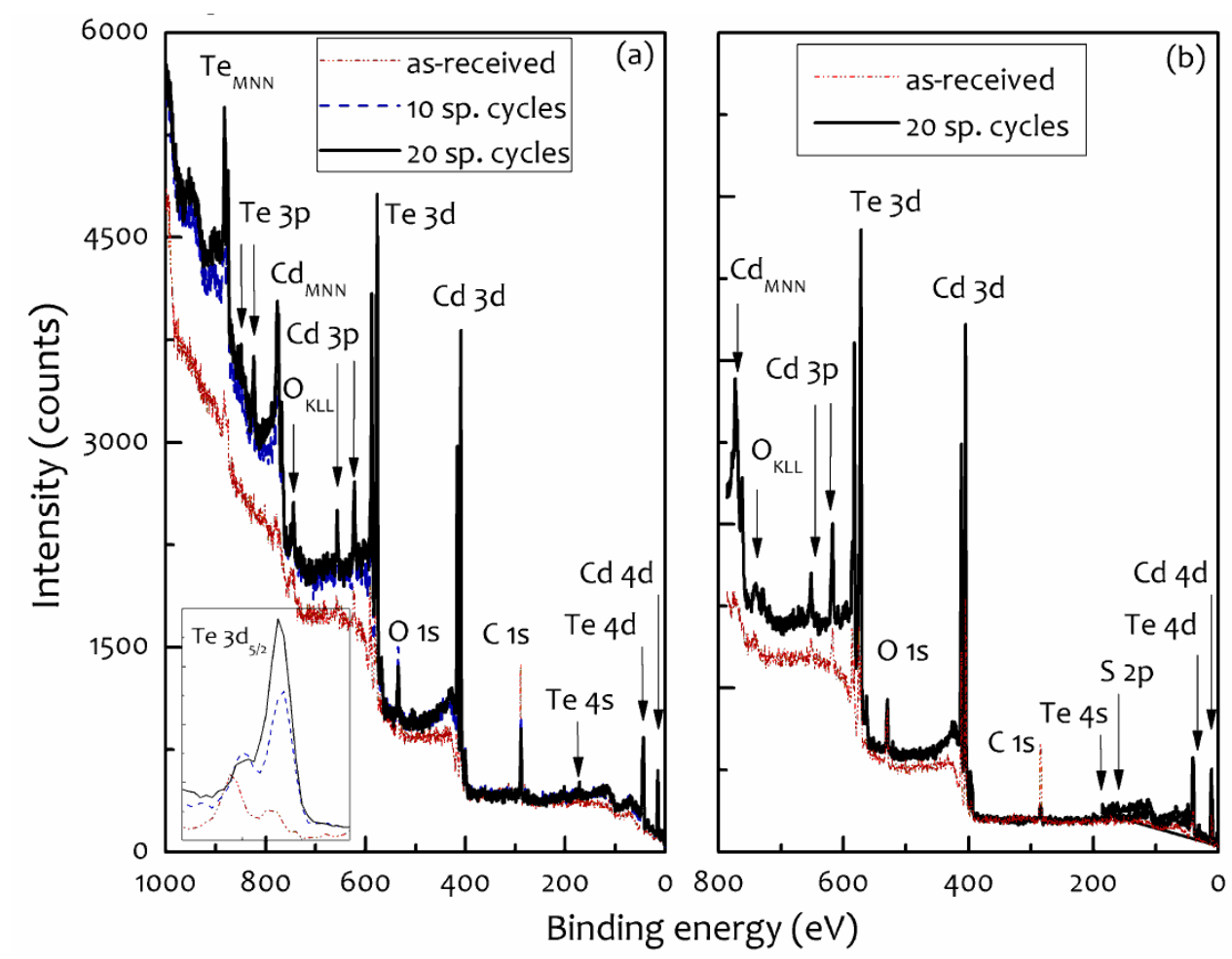

Fig. 4. (a) Survey XPS spectra of the CFT sample: as-received (dash-dot line); after 10 sputtering cycles (dash line); after 20 sputtering cycles (full line). Characteristic Te $3 \mathrm{~d}_{5 / 2}$ photoelectron line is shown in the inset. (b) Survey XPS spectra of the CFTS sample: as-received (dash-dot line); after 20 sputtering cycles (full line).

\subsubsection{Analysis of the characteristic photoelectron lines}

According to the survey XPS spectra shown in Fig. 4, at least three regions can be distinguished in the near-surface region of investigated samples. The outermost layer of carbonaceous impurities lies on the top of the oxidized surface layer which covers the bulk. Characteristic $\mathrm{Cd}$ and $\mathrm{Te} 3 \mathrm{~d}_{5 / 2}$ photoelectron lines taken from both investigated samples are shown in Fig. 5a-d. The position of $\mathrm{Cd} 3 \mathrm{~d}_{5 / 2}$ line does not carry reliable information on the $\mathrm{Cd}$ bonds [45-47], due to its small chemical 
shift. Low sensitivity to the chemical environment makes the $\mathrm{Cd} 3 \mathrm{~d}_{5 / 2}$ line a good energy reference for different $\mathrm{Cd}$ compounds. The bond identification in these materials is usually based on the position of other lines with respect to the main $\mathrm{Cd} 3 \mathrm{~d}_{5 / 2}$ photoelectron line $[30,48,49]$. The fitting results of the $\mathrm{Cd}$ and $\mathrm{Te} 3 \mathrm{~d}_{5 / 2}$ lines are summarized in Table 2. After the background subtraction, the lines were fitted to the pseudo-Voigt profiles representing a product of $70 \%$ Lorentzian (L) and $30 \%$ Gaussian $(\mathrm{G})$ profiles, i.e. GL(70). In both samples, the Te $3 \mathrm{~d}_{5 / 2}$ line was fitted with two components of the same width. The dominant $\mathrm{Te}_{1}$ component is shifted with respect to $\mathrm{Cd} 3 \mathrm{~d}_{5 / 2}$ line for $167.3 \mathrm{eV}$ in CFT and $167.4 \mathrm{eV}$ in CFTS sample (see Table 2), which matches well Cd-Te bonds in CdTe $[45,48]$. The difference between $\mathrm{Te}_{1}$ and $\mathrm{Te}_{2}$ components $(3.0 \mathrm{eV}$ in CFT; $3.3 \mathrm{eV}$ in CFTS sample) implies that $\mathrm{Te}_{2}$ originates from some Te-oxide(s) $[45,50]$. Change of the ratio between $\mathrm{Te}_{1}$ and $\mathrm{Te}_{2}$ relative intensities upon sputtering (see Fig. 4a) clearly indicates that $\mathrm{Te}_{2}$ originates from an oxide layer which covers CdTe bulk-like matrix.

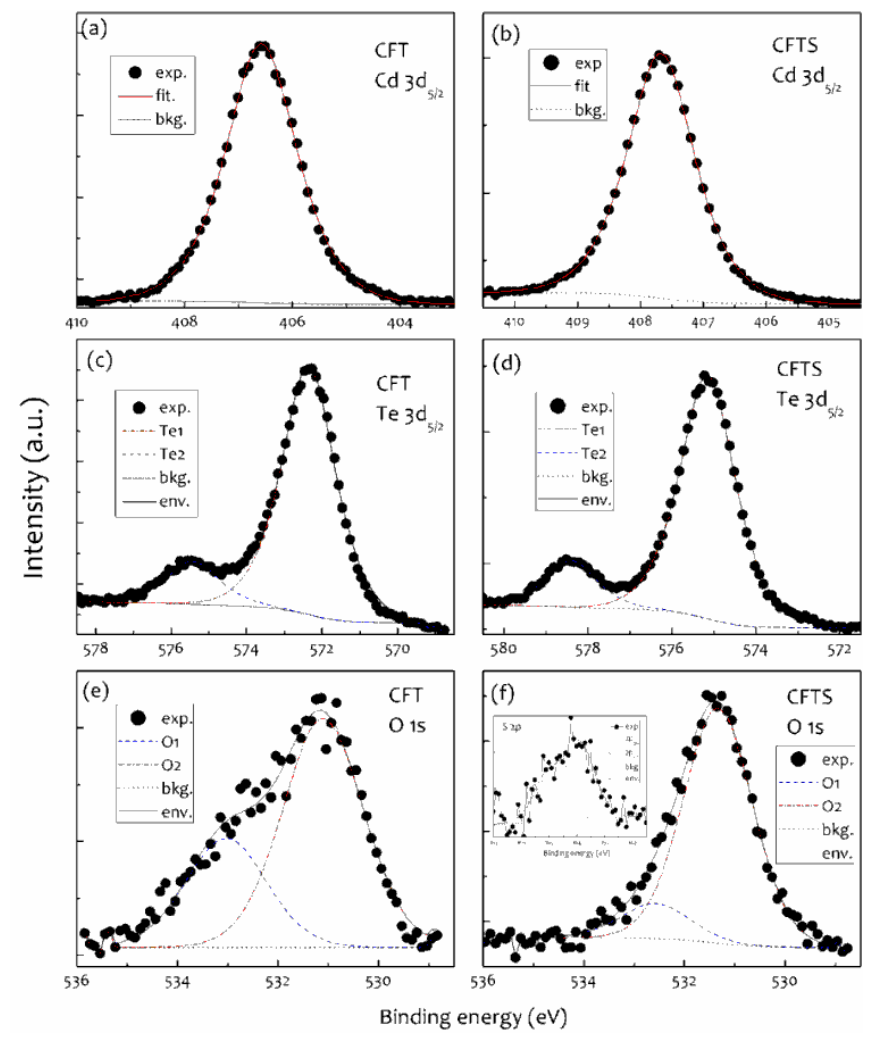

Fig. 5. The experimental Cd $3 d_{5 / 2}$ photoelectron line and its fit in (a) CFT sample and (b) CFTS sample; the experimental Te $3 d_{5 / 2}$ photoelectron line and its fit in (c) CFT sample and (d) CFTS sample. The two components of $\mathrm{Te} 3 \mathrm{~d}_{5 / 2}$ line correspond to bulk $\left(\mathrm{Te}_{1}\right)$ and oxide layer $\left(\mathrm{Te}_{2}\right)$. The experimental O 1s photoelectron line and its fit in (e) CFT and (f) CFTS sample. The two components of the $\mathrm{O} 1 \mathrm{~s}$ line correspond to impurity $\left(\mathrm{O}_{1}\right)$ and oxide layer $\left(\mathrm{O}_{2}\right)$. Fit of the experimental S 2p XPS line of CFTS sample is shown in inset. The background (bkg) calculated using the Shirley algorithm is represented with dotted line and the envelope (env) with full line. 
Table 2

Results of $\mathrm{Cd}$ and $\mathrm{Te} 3 \mathrm{~d}_{5 / 2}$ lines fitting. Some reference data $[45,46,51]$ are given for comparison.

\begin{tabular}{|c|c|c|c|c|c|c|c|c|}
\hline & $\mathrm{Cd} 3 \mathrm{~d}_{5 / 2}$ & & & $3 d_{5 / 2}$ & & $\mathrm{Te}_{1}-\mathrm{Cd}$ & $\mathrm{Te}_{2}-\mathrm{Cd}$ & $\mathrm{Te}_{2}-\mathrm{Te}_{1}$ \\
\hline & Position & $\mathrm{Te}_{1}(\mathrm{CdTe}$ & & $\mathrm{Te}_{2}$ (oxide & lyer) & $(\mathrm{eV})$ & $(\mathrm{eV})$ & $(\mathrm{eV})$ \\
\hline & $(\mathrm{eV})$ & $\begin{array}{l}\text { Position } \\
(\mathrm{eV})\end{array}$ & $\begin{array}{l}\text { Rel. } \\
\text { int. (\%) }\end{array}$ & $\begin{array}{l}\text { Position } \\
(\mathrm{eV})\end{array}$ & $\begin{array}{l}\text { Rel. int. } \\
(\%)\end{array}$ & & & \\
\hline CFT & 405.8 & 573.1 & 85.2 & 576.1 & 14.8 & 167.3 & 170.3 & 3.0 \\
\hline CFTS & 407.7 & 575.1 & 84.8 & 578.4 & 15.2 & 167.4 & 170.7 & 3.3 \\
\hline $\mathrm{CdTe}$ & $405.5[45]$ & 572.5 & - & $576.0[45]$ & - & 167.0 & 170.5 & $3.5[45]$ \\
\hline $\mathrm{CdTeO}_{3}$ & 405.5 [46] & - & - & $575.7[51]$ & - & - & 170.2 & - \\
\hline
\end{tabular}

The experimental O 1s photoelectron line in CFT and CFTS sample is shown in Fig. 5e and Fig. 5f, respectively. In both samples the O 1s line was fitted with two GL(30) pseudo-Voigt profiles of the same width, corresponding to organic impurity $\left(\mathrm{O}_{1}\right)$ and oxide-related contribution $\left(\mathrm{O}_{2}\right)$. Table 3 summarizes the fitting results. The $\mathrm{O} 1 \mathrm{~s}$ binding energy in the compounds of interest falls within a narrow binding energy range (see Table 3) [31, 52]. Therefore, instead of absolute line positions we again used the relative positions of relevant XPS lines/line components. The difference between $\mathrm{Te}_{2}$ and $\mathrm{O}_{2}$ and between $\mathrm{O}_{2}$ and Cd positions (see Table 3), implies that the $\mathrm{O}_{2}$ component in both investigated samples can be attributed to either $\mathrm{CdTeO}_{3}$ or $\mathrm{TeO}_{2}$, whereas $\mathrm{CdO}$ phase can be excluded.

\section{Table 3}

Results of the $\mathrm{O} 1 \mathrm{~s}$ line fitting, together with the position of $\mathrm{O}$ 1s line in some compounds of interest [31].

\begin{tabular}{|c|c|c|c|c|c|c|}
\hline \multirow{2}{*}{ Sample } & \multicolumn{2}{|c|}{$\mathrm{O}_{2}$ (oxide layer) } & \multicolumn{2}{|c|}{$\mathrm{O}_{1}$ (impurity layer) } & \multirow{2}{*}{$\begin{array}{l}\mathrm{Te}_{2}-\mathrm{O}_{2} \\
(\mathrm{eV})\end{array}$} & \multirow{2}{*}{$\begin{array}{l}\mathrm{O}_{2}-\mathrm{Cd} \\
(\mathrm{eV})\end{array}$} \\
\hline & $\begin{array}{l}\text { Position } \\
(\mathrm{eV})\end{array}$ & $\begin{array}{l}\text { Rel. int. } \\
(\%)\end{array}$ & $\begin{array}{l}\text { Position } \\
(\mathrm{eV})\end{array}$ & $\begin{array}{l}\text { Rel. int. } \\
(\%)\end{array}$ & & \\
\hline CFT & 530.4 & 68.3 & 532.3 & 31.7 & 45.7 & 124.6 \\
\hline CFTS & 532.8 & 70.4 & 533.4 & 29.6 & 45.6 & 125.1 \\
\hline $\mathrm{TeO}_{2}$ & $530.1-530.7$ & - & - & - & $45.5-45.9$ & - \\
\hline $\mathrm{CdTeO}_{3}$ & 530.4 & - & - & - & 45.3 & 124.9 \\
\hline $\mathrm{CdO}$ & $528.8-531.5$ & - & - & - & - & $126.6-127.3$ \\
\hline $\mathrm{CdSO}_{4}$ & 530.6 & - & 532.9 & - & - & 125.2 \\
\hline
\end{tabular}


High resolution spectrum of the $S$ 2p photoelectron line of CFTS sample and its fit are shown in the inset of Fig. 5f. The two contributions corresponding to $\mathrm{S} 2 \mathrm{p}_{3 / 2}$ (positioned at $163.9 \mathrm{eV}$ ) and $\mathrm{S} 2 \mathrm{p}_{1 / 2}$ (positioned at $165.1 \mathrm{eV}$ ) were subjected to appropriate constraints, i.e. the intensity ratio is fixed to the theoretical 1:2 and the peak separation is set to $1.18 \mathrm{eV}$ [31]. The difference between $\mathrm{Cd} 3 \mathrm{~d}_{5 / 2}$ and $\mathrm{S} 2 \mathrm{p}_{3 / 2}$ line positions in CFTS sample is $243.8 \mathrm{eV}$, which is close to that in CdS (243.6 [49], $243.4 \mathrm{eV}$ [53]), but much larger than in $\mathrm{CdSO}_{4}$ (236.6 eV [49]). Presence of sulfate phase can therefore be excluded. Although formation of sulfate surface layer on sulfide materials exposed to oxidizing environment $\left(\mathrm{H}_{2} \mathrm{O}\right.$ vapor, $\left.\mathrm{O}_{2}\right)$ [54] is thermodynamically favorable [55] we did not observe any $\mathrm{S}-\mathrm{O}$ related phases probably due to lack of adequate amount of available oxygen. Unfortunately, EXAFS data on S K-edge were not accessible, and thus we were not able to extract more information on its local and electronic structure.

Carbon 1s line was in both samples fitted with two contributions (not shown). Saturated hydrocarbons ( $\mathrm{C}-\mathrm{C}$ and $\mathrm{C}-\mathrm{H}$ bonds) [52] dominate the line intensity (88.3\% in CFT; $76.2 \%$ in CFTS sample), while the rest is is attributed to $\mathrm{C}-\mathrm{O}$ bonds (11.7 \% in CFT; $23.8 \%$ in CFTS sample).

\subsubsection{In-depth composition and structure analysis}

While the phase imaging performed by AFM showed that the top monolayer of CFTS sample is uniform, the observed influence of ion sputtering on the structure of the XPS spectra (see Fig. 4) and the results of the analysis of the characteristic photoelectron lines (see Fig. 5) strongly support the two-layer modeling of the surface structure. That is, a layer of hydrocarbon impurities with a relatively small amount of oxygen covers a thin layer of tellurium-containing oxide. Below the oxide layer we expect to have uniform bulk material down to the information depth of the technique ( $\sim-10 \mathrm{~nm})$. To estimate composition of the three regions and the thicknesses of surface over-layers, the algorithm for the quantification of in-depth non-uniform surfaces, introduced in Section 3, will be followed.

Table 4 and Table 5 contain the relevant data of materials and photoelectron lines of interest necessary for in-depth composition and structure analysis. Energy gap $\left(E_{g}\right)$, number of valence electrons $\left(N_{v}\right)$, density $(\rho)$, kinetic energy of photoelectrons $(E)$ and the asymmetry parameter $(\beta)$ are needed to calculate IMFPs and EALs. Average EALs are determined from the TPP-2M calculated inelastic mean free paths (IMPFs) [56] using an algorithm based on the electron 
transport theory. Due to low intensity of the oxide phase, we expect to have approximately one monolayer thick oxide layer. The hydrocarbon impurity layer is, however, expected to be much thicker. Therefore, the calculations of EALs were performed for $d_{o}=0.3 \mathrm{~nm}$ and $d_{c}=2.5 \mathrm{~nm}$. In general, EALs are slowly varying functions of the layer thickness and thus their relative change is only a few percent in the thickness range $0-3 \mathrm{~nm}$. Parameter $N_{v}$ is determined using the recommended energy cut-off of $14 \mathrm{eV}$ [57].

\section{Table 4}

Data related to the photoelectron lines of interest: $E$ - kinetic energy of photoelectrons, $\sigma_{/} \sigma_{C}-$ Scofield photoelectric cross section [58] normalized to the value of C 1s line, $\beta$ - asymmetry parameter [59].

\begin{tabular}{llllll}
\hline Line & $\mathrm{S} 2 \mathrm{p}$ & $\mathrm{C} 1 \mathrm{~s}$ & $\mathrm{O} 1 \mathrm{~s}$ & $\mathrm{Cd} \mathrm{3d_{5/2 }}$ & $\mathrm{Te} 3 \mathrm{~d}_{5 / 2}$ \\
\hline $\mathrm{E}(\mathrm{eV})$ & 1091 & 967 & 722 & 848 & 681 \\
\hline$\sigma / \sigma_{\mathrm{C}}$ & 1.74 & 1 & 2.85 & 11.91 & 17.70 \\
\hline$\beta$ & 1.225 & 2 & 2 & 1.194 & 1.131 \\
\hline
\end{tabular}

\section{Table 5}

Parameters related to materials of interest: $\rho$ - density, $\mathrm{M}$ - molar mass, $\mathrm{N}$ - number of atoms per unit volume, $\mathrm{E}_{\mathrm{g}}$ - energy gap, $\mathrm{N}_{\mathrm{v}}$ - number of valence electrons per molecule, and L - effective attenuation lengths.

\begin{tabular}{lllll}
\hline Material & $\mathrm{C}_{26} \mathrm{H}_{54}$ & $\mathrm{CdTe}$ & $\mathrm{TeO}_{2}$ & $\mathrm{CdTeO}_{3}$ \\
\hline$\rho\left(\mathrm{g} / \mathrm{cm}^{3}\right)$ & 0.78 & 6.2 & 5.67 & 6.41 \\
\hline $\mathrm{M}(\mathrm{g} / \mathrm{mol})$ & 366.7 & 240 & 159.6 & 288.0 \\
\hline $\mathrm{N}\left(10^{22} \mathrm{~cm}^{-3}\right)$ & 10.24 & 3.12 & 6.42 & 6.7 \\
\hline $\mathrm{E}_{\mathrm{g}}(\mathrm{eV})$ & 6.0 & 1.5 & 3.5 & 3.3 \\
\hline $\mathrm{N}_{\mathrm{v}}$ & 158 & 18 & 14 & 30 \\
\hline $\mathrm{L}_{\mathrm{C}}(\mathrm{nm})$ & 3.122 & - & - & - \\
\hline $\mathrm{L}_{\mathrm{O}}(\mathrm{nm})$ & 2.458 & - & 1.335 & 1.223 \\
\hline $\mathrm{L}_{\mathrm{Cd}}(\mathrm{nm})$ & 2.803 & 1.656 & 1.518 & 1.390 \\
\hline $\mathrm{L}_{\mathrm{Te}}(\mathrm{nm})$ & 2.344 & 1.405 & 1.274 & 1.167 \\
\hline $\mathrm{L}_{\mathrm{s}}(\mathrm{nm})$ & 3.448 & 1.836 & - & 1.707 \\
\hline
\end{tabular}

The first step in the proposed algorithm for in-depth surface analysis is to estimate the composition of each region (bulk, oxide layer and impurity layer) which will be consistent with the bonds 
identified in the analysis of characteristic photoelectron lines. From the perspective of electron transport properties (i.e. elastic and inelastic scattering of photoelectrons), the XPS-probed bulklike region is modeled as CdTe matrix. In CFTS sample, some of the tellurium atoms are replaced with sulfur according to composition analysis.

The phase identification of the contamination layer is particularly complex issue (as already mentioned). The dominant $\mathrm{C} 1 \mathrm{~s}$ line contribution is in both investigated samples attributed to adventitious carbon (i.e. saturated hydrocarbons). Hence this layer is, likewise [60], modeled as a paraffin matrix $\left(\mathrm{C}_{26} \mathrm{H}_{54}\right)$ in which some of the carbon atoms are substituted with oxygen. Carbonto-oxygen concentration ratio is determined from the analysis of the $\mathrm{C} 1 \mathrm{~s}$ and $\mathrm{O}$ 1s lines $(7.55$ in CFT and 3.20 in CFTS sample). The estimated composition of impurity layer is $67.5 \% \mathrm{H}, 28.7 \%$ $\mathrm{C}$ and $3.8 \% \mathrm{O}$ in CFT sample and $67.5 \% \mathrm{H}, 24.8 \% \mathrm{C}$ and $7.7 \% \mathrm{O}$ in CFTS sample.

To estimate oxygen-to-tellurium concentration ratio in the oxide layer, the following ratio between measured $\mathrm{O}_{2}$ and $\mathrm{Te}_{2}$ intensities (not given) is used:

$$
\frac{S_{o}^{\text {oxide }}}{S_{T e}^{\text {oxide }}}=\frac{\frac{I_{o}^{\text {oxide }} \cdot E_{o}}{\sigma_{o} \cdot L_{o}^{\text {oxide }}}}{\frac{I_{T e}^{\text {oxide }} \cdot E_{T e}}{\sigma_{T e} \cdot L_{T e}^{\text {oxide }}}} .
$$

Given that due to similar kinetic energies EALs and transmission functions of $\mathrm{O} 1 \mathrm{~s}$ and Te $3 \mathrm{~d}_{5 / 2}$ lines only slightly differ (see Tables 4 and 5), we can write:

$$
\frac{S_{o}^{\text {oxide }}}{S_{T e}^{\text {oxide }}} \approx \frac{\frac{I_{0}^{\text {oxide }}}{\sigma_{O}}}{\frac{I_{T e}^{\text {oxide }}}{\sigma_{T e}}} .
$$

The oxygen-to-tellurium concentration ratio calculated using the upper expression is found to be close to three in both investigated samples, which implies that the oxide layer consists of $\mathrm{CdTeO}_{3}$. Absence of $\mathrm{CdO}$ phase in both samples excludes possibility of a mixture between two binary oxide phases (e.g. $\mathrm{TeO}_{2}$ and $\mathrm{CdO}$ ). Thickness of the oxide layer, estimated from the measured $\mathrm{Te}_{1}$ and $\mathrm{Te}_{2}$ intensities (not given) using Eq. (10), is $d_{0}=0.25 \mathrm{~nm}$ in CFT and $d_{0}=0.23 \mathrm{~nm}$ in CFTS sample.

Once the composition of the oxide layer and its thickness $\left(d_{o}\right)$ are known, the contribution of cadmium to the bulk-like phase $\left(I_{C d}{ }^{b}\right)$ can be readily calculated from the experimentally measured intensity of the $\mathrm{Cd} 3 \mathrm{~d}_{5 / 2}$ line $\left(I_{C d}\right)$ and the ratio $I_{C d}{ }^{o} I_{C d}{ }^{b}$ calculated via Eq. (9) as:

$$
I_{C d}^{b}=\frac{I_{C d}}{1+\frac{I_{C d}^{o}}{I_{C d}^{b}}}
$$

The contribution of cadmium to the oxide phase is then $I_{C d}{ }^{o}=I_{C d}-I_{C d}{ }^{b}$. 
In the next step, Eq. (14) is used to derive the effective intensities $\left(S_{i}^{m}\right)$ of each line/line contribution from the experimentally measured intensities $\left(I_{i}^{m}\right)$. These experimentally-derived effective intensities were subsequently normalized using Eq. (18) and apparent relative concentrations $\left(x_{i}{ }^{*}\right)$ were obtained via Eq. (19). Table 6 summarizes the results for apparent relative concentrations of all elements detected at the surfaces of investigated samples. The statistical uncertainties of the experimental measurements were evaluated under assumption that the count rates obey the Poisson distribution (so-called shot noise).

\section{Table 6}

Experimentally determined apparent relative concentrations of the elements detected at the surfaces of investigated samples.

\begin{tabular}{|c|c|c|c|c|c|c|c|c|c|c|}
\hline \multirow[t]{2}{*}{ Sample } & \multicolumn{10}{|c|}{ Apparent relative concentration $x_{i}{ }^{*}(\%)$} \\
\hline & \multicolumn{2}{|c|}{$x_{C}{ }^{*}$} & \multicolumn{2}{|c|}{$x_{O}{ }^{*}$} & \multicolumn{2}{|c|}{$x_{C d}^{*}$} & \multicolumn{2}{|c|}{$x_{T e}^{*}$} & $x_{S}{ }^{*}$ & $x_{O}{ }^{*} / x_{T e}{ }^{*}$ \\
\hline \multirow[t]{3}{*}{ CFT } & \multicolumn{2}{|c|}{$34.2 \pm 2.1$} & \multicolumn{2}{|c|}{$16.0 \pm 2.0$} & \multicolumn{2}{|c|}{$26.6 \pm 1.4$} & \multicolumn{2}{|c|}{$23.2 \pm 1.3$} & - & in oxide \\
\hline & $\mathrm{C}-\mathrm{C}$ & $\mathrm{C}-\mathrm{O}$ & impurities & oxide & oxide & bulk & oxide & bulk & - & 2.7 \\
\hline & 30.1 & 4.1 & 5.1 & 10.9 & 3.3 & 23.3 & 3.4 & 19.8 & & \\
\hline \multirow[t]{3}{*}{ CFTS } & \multicolumn{2}{|c|}{$19.3 \pm 2.7$} & \multicolumn{2}{|c|}{$18.6 \pm 1.9$} & \multicolumn{2}{|c|}{$33.0 \pm 1.9$} & \multicolumn{2}{|c|}{$26.3 \pm 1.7$} & $2.8 \pm 0.7$ & 3.3 \\
\hline & $\mathrm{C}-\mathrm{C}$ & $\mathrm{C}-\mathrm{O}$ & impurities & oxide & oxide & bulk & oxide & bulk & & \\
\hline & 14.7 & 4.6 & 5.5 & 13.1 & 3.6 & 29.4 & 4.0 & 22.3 & & \\
\hline
\end{tabular}

In the following step, the effective intensities $\left(S_{i}^{m}\right)$ are expressed as a function of the contamination layer thickness $\left(d_{c}\right)$ via Eqs. (15) - (17), using previously calculated thickness of the oxide layer $\left(d_{o}\right)$ and the data given in Table 4 and Table 5. Corresponding apparent relative concentrations (obtained from the normalized effective intensities similarly to the previous step), as a function of $d_{c}$ are presented in Fig. 6 . The final step is to determine the value $d_{c}$ for which calculated apparent relative concentrations of all elements detected at the surface (see Fig. 6) match corresponding experimentally-derived values (see Table 6) within corresponding experimental uncertainties. The smallest relative uncertainty is obtained for apparent $\mathrm{Cd}$ concentration $\left(x_{C d}{ }^{*}\right)$ owing to the highest intensity of the $\mathrm{Cd} 3 \mathrm{~d}_{5 / 2}$ line (see Table 2). Therefore, the $x_{C d}{ }^{*}$ values, as the most reliable, served to estimate the impurity layer thicknesses $\left(d_{c}\right)$ which fulfills the condition $x_{C d}{ }^{*}\left(d_{c}\right)=x_{C d}{ }^{*}$. In that way, we estimated that for $x_{C d}{ }^{*}=26.6 \%$ in CFT sample (see Table 6) the impurity layer is $1.49 \mathrm{~nm}$ thick (see Fig. 6a), while for $x_{C d}{ }^{*}=33.0 \%$ in CFTS sample (see Table 6) the impurity layer is $0.91 \mathrm{~nm}$ thick (see Fig. 6b). 


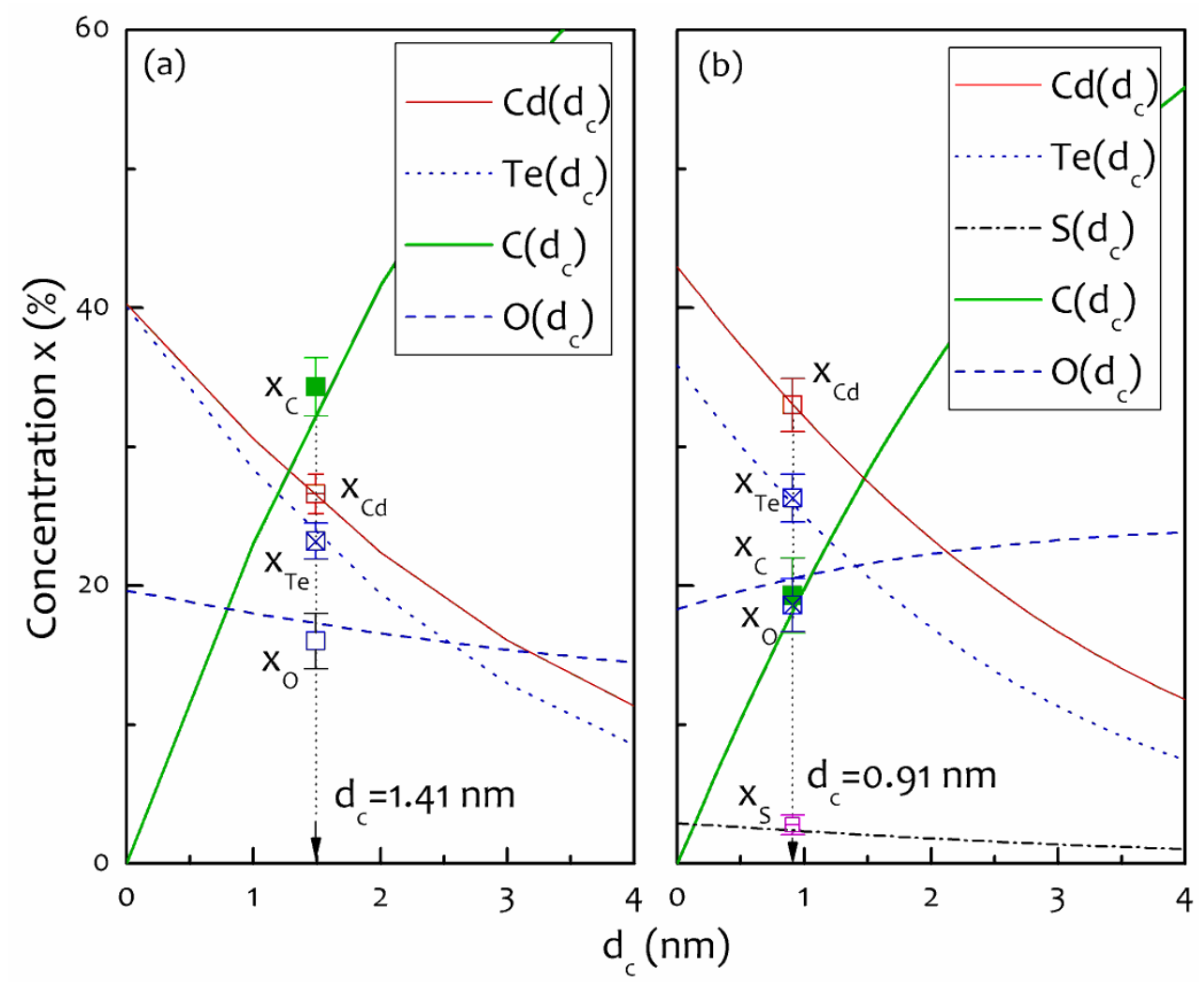

Fig. 6. Apparent relative concentrations as a function of impurity layer thickness $\left(d_{c}\right)$ in (a) CFT sample and (b) CFTS sample. Experimentally determined values with appropriate error bars are represented with squares. For $d_{c}=1.49 \mathrm{~nm}$ in CFT, and $d_{c}=0.91 \mathrm{~nm}$ in CFTS sample, apparent relative concentrations of all elements are inside corresponding experimental uncertainties which proves that the estimated surface structures are compatible with experimental results (see text for more details).

The composition of the bulk-like region of CFT sample consistent with the experimental results comprises stoichiometric CdTe. This structure is covered with $0.25 \mathrm{~nm}$ thick $\mathrm{CdTeO}_{3}$ and $1.49 \mathrm{~nm}$ thick impurity layer. However, although the apparent relative atomic concentrations (i.e. concentrations one would obtain using standard XPS composition analysis) indicate higher $\mathrm{Cd}$ concentration with respect to $\mathrm{Te}$ (see Table 6), in-depth composition analysis reveals that both the oxide layer and the bulk-like region are stoichiometric. This is to be expected, since the electronic structure of non-polar $\mathrm{CdTe}(110)$ surface (terminated by $\mathrm{Cd}$ and $\mathrm{Te}$ atoms) preserves almost ideal bulk-like form. According to our analysis, the main reason for the observed Cd-excess (which has been also reported for e.g. as-deposited CdTe thin film [61] and $\mathrm{CdTeO}_{3}$ thin layers grown on CdTe [50]), can be ascribed to in-depth non-uniformity of the sample's surface. The contamination 
and oxide over-layers attenuate more $\mathrm{Te} 3 \mathrm{~d}$ line than the $\mathrm{Cd} 3 \mathrm{~d}$ line due to the different kinetic energies of the corresponding photoelectrons.

Results of the in-depth composition analysis of CFTS sample revealed that its near-surface region is covered with approximately $0.23 \mathrm{~nm}$ thick $\mathrm{CdTeO}_{3}$ layer which lays underneath the $0.91 \mathrm{~nm}$ thick hydrocarbon impurity layer. However, with respect to the nominal composition $(49.5 \% \mathrm{Cd}$, $0.05 \% \mathrm{Fe}, 48.5 \% \mathrm{Te}$ and $1.5 \% \mathrm{~S}$ ), the bulk-like layer immediately below the oxide layer appears to be somewhat enriched in S and consequently Te-deficient (53\% Cd, $43 \%$ Te and $4 \% \mathrm{~S}$ ). Sulfur tends to segregate to the surface in order to minimize surface free energy $\gamma[62]\left(\gamma_{\mathrm{CdTe}}=0.85 \mathrm{~J} / \mathrm{m}^{2}\right.$ [63], $\gamma_{\mathrm{CdS}}=0.29 \mathrm{~J} / \mathrm{m}^{2}$ [64]). Besides, small diffusion barrier of $\mathrm{S}$ in CdTe $(0.65 \mathrm{eV})$ enables its efficient migration at room temperature. Atomic rearrangement in the near surface region ( $\mathrm{S}$ moves towards and Te away from the surface) that has already been observed at the interfaces of the $\mathrm{CdTe} / \mathrm{CdS}$ polycrystalline grains [66], most likely takes place before the sample had been exposed to air.

\section{Conclusion}

In conclusion, X-ray absorption fine structure (XAFS) studies of the local structural and electronic properties around $\mathrm{Fe}$ in multi-component $\mathrm{Cd}_{0.99} \mathrm{Fe}_{0.01} \mathrm{Te}_{0.97} \mathrm{~S}_{0.03}$ revealed that Fe shows preferences for paring with $\mathrm{S}$. The local distortions of the host CdTe lattice are confined to Fe-immediate surrounding, without appreciable influence on the atoms located beyond the second coordination shell. Despite well defined local structure in the bulk, the near-surface region of $\mathrm{Cd}_{0.97} \mathrm{Fe}_{0.03} \mathrm{Te}$ and $\mathrm{Cd}_{0.99} \mathrm{Fe}_{0.01} \mathrm{Te}_{0.97} \mathrm{~S}_{0.03}$ systems is completely depleted from $\mathrm{Fe}$, as revealed by $\mathrm{X}$-ray Photoelectron Spectroscopy (XPS). Absence of Fe from the sub-surface region and specific atomic redistribution is possibly caused by surface oxidation. Careful characterization of the near-surface region was therefore conducted in order to better understand the influence of oxygen and the extent to which long term air exposure affects the surface composition and its structure. However, since the standard XPS composition analysis based on atomic sensitivity factors (ASFs) is valid only if the sample consists of a single phase, we have introduced a novel standard-free approach which can be used to evaluate the surface structure of in-depth non-uniform materials. The algorithm is applicable to materials consisting of the bulk-like region ( $\sim \mathrm{nm}$ thick) covered with two laterally uniform thin over-layers. The only requirement is that each of the three regions consists of a single phase. Each photoelectron line and/or line contribution originating from a different region is assigned an effective intensity, the quantity which can be (i) derived from experimentally measured 
line intensities and (ii) expressed as a function of relative atomic concentrations and thicknesses of the two overlayers. Normalized effective intensities, attributed to each line/line-component, are denoted as apparent relative concentrations. The ultimate goal of the two-layer model is to find the structure for which the experimentally-derived and calculated apparent relative concentrations coincide in the frame of the experimental error. Results of the in-depth composition analysis revealed that both samples are covered with approximately one monolayer thick $\mathrm{CdTeO}_{3}$. Furthermore, while the bulk-like region of the $\mathrm{Cd}_{0.97} \mathrm{Fe}_{0.03} \mathrm{Te}$ sample is stoichiometric $\mathrm{CdTe}$, the top-most bulk-like layer of $\mathrm{Cd}_{0.99} \mathrm{Fe}_{0.01} \mathrm{Te}_{0.97} \mathrm{~S}_{0.03}$ sample is found to be somewhat enriched in $\mathrm{S}$ (with respect to its nominal composition). Surface segregation of $\mathrm{S}$ is most likely driven by the minimization of the surface free energy and takes place independently from the air exposure.

\section{Acknowledgements}

The research leading to these results has received funding from the European Community's Seventh Framework programme (FP7/2007-2013) under the Grant agreement $N^{\circ} 226716$ and is supported by Serbian Ministry of Education, Science and Technological Development under the Grants III45003 and III45005, the Program of scientific and technological cooperation between Republic of Serbia and Republic of Portugal under the Grant No. 451-03-02328/2012-14/03 and the Portuguese Research Grant Pest-OE/FIS/UI0068/2013 through FCT-MEC. HASYLAB @ DESY is acknowledged for providing the beam time for XAFS measurements.

\section{Data availability}

The raw/processed data required to reproduce these findings cannot be shared at this time as the data also forms part of an ongoing study.

\section{References}

[1] S.B. Mirov, V.V. Fedorov, D. Martyshkin, I.S. Moskalev, M. Mirov, S. Vasilyev, Progress in Mid-IR Lasers Based on Cr and Fe-Doped II-VI Chalcogenides, IEEE J. Sel. Top. Quant. 21 (2015) 16017-19.

[2] P. Capper (Ed.), Narrow-gap II-VI Compounds for Optoelectronic and Electromagnetic Applications, Chapman \& Hall (UK), 1997. 
[3] M. Ebrahim-Zadeh, I.T. Sorokina (Eds.), Mid-infrared coherent sources and applications, Springer, 2005.

[4] S.B. Singh, M.V. Limaye, S K. Date, S. Gokhale, S.K. Kulkarni, Iron substitution in CdSe nanoparticles: Magnetic and optical properties, Phys. Rev. B 80 (2009) 235421-10.

[5] K. Kaur, G.S. Lotey, N.K. Verma, Optical and magnetic properties of Fe-doped CdS dilute magnetic semiconducting nanorods, J. Mater. Sci.: Mater. Electron. 25 (2014) 2605-2610.

[6] X. Wang, C. Chen, A. Liu, R. Wang, Effective interband g factors in diluted magnetic semiconductor $\mathrm{Cd}_{1-\mathrm{x}} \mathrm{Fe}_{\mathrm{x}} \mathrm{Te}, \mathrm{J}$. Appl. Phys. 80 (1996) 4421-4424.

[7] S.M. Islam and B.A. Bunker, Studies of atomic correlations in quaternary semiconductor alloys using the extended X-ray absorption fine structure technique, Phys. Lett. A 156 (1991) $247-252$.

[8] I. Radisavljević, J. Trigueiro, N. Bundaleski, M. Medić, N. Romčević, O.M.N.D. Teodoro, M. Mitrić, N. Ivanović, XAFS and XPS analysis of $\mathrm{Zn}_{0.98} \mathrm{Fe}_{0.02} \mathrm{Te}_{0.91} \mathrm{Se}_{0.09}$ semiconductor, J. Alloys Compd. 632 (2015) 17-22.

[9] I. Radisavljević, N. Novaković, N. Romčević, M. Mitrić, B. Kuzmanović, S. Bojanić, N. Ivanović, Electronic aspects of formation and properties of local structures around $\mathrm{Mn}$ in $\mathrm{Cd}_{1-\mathrm{x}} \mathrm{Mn}_{\mathrm{x}} \mathrm{Te}_{1-\mathrm{y}} \mathrm{Se}_{\mathrm{y}}$, Mat. Chem. Phys. 167 (2015) 236-245.

[10] V. Tomashyk, Quaternary Alloys Based on II-VI Semiconductors, CRC Press, 2014.

[11] A.D. Martinez, D.V. Martyshkin, R.P. Camata, V.V. Fedorov, S.B. Mirov, Crystal field engineering of transition metal doped II-VI ternary and quaternary semiconductors for mid-IR tunable laser applications, Opt. Mater. Express 5 (2015) 2036-2046.

[12]A. Twardowski, Magnetic properties of Fe-based diluted magnetic semiconductors, J. Appl. Phys. 67 (1990) 5108-5113.

[13]A. Mycielski, M. Arciszewska, W. Dobrowolski, C. Rigaux, A. Mauger, C. Testelin, C. Julien, A. Lenard, M. Guillot, B. Witkowska, M. Menant, II-VI Semiconductors doped with transition metals other than Mn, Phys. Scr. T39 (1991) 119-123.

[14]R. Hu, E.S. Bozin, J.B. Warren, C. Petrovic, Superconductivity, magnetism, and stoichiometry of single crystals of $\mathrm{Fe}_{1+y}\left(\mathrm{Te}_{1-\mathrm{x}} \mathrm{S}_{\mathrm{x}}\right)_{\mathrm{z}}$, Phys. Rev. B 80 (2009) 2-8.

[15]P. Zajdel, P.Y. Hsieh, E.E. Rodriguez, N.P. Butch, J.D. Magill, J. Paglione, P. Zavalij, M.R. Suchomel, M.A. Green, Phase Separation and Suppression of the Structural and Magnetic Transitions in Superconducting Doped Iron Tellurides $\mathrm{Fe}_{1+\mathrm{x}} \mathrm{Te}_{1-\mathrm{y}} \mathrm{S}_{\mathrm{y}}$, J. Am. Chem. Soc. 132 (2010) 13000-13007. 
[16] Y. Mizuguchi, K. Deguchi, Y. Kawasaki, T. Ozaki, M. Nagao, S. Tsuda, T. Yamaguchi, Y. Takano, Superconductivity in oxygen-annealed FeTe ${ }_{1-\mathrm{x}} \mathrm{S}_{\mathrm{x}}$ single crystal, 109 (2011) 013914 4.

[17]S. Girish Kumar, K.S.R. Koteswara Rao, Physics and chemistry of CdTe/CdS thin film heterojunction photovoltaic devices: fundamental and critical aspects, Energy Environ. Sci. 7 (2014) 45-102.

[18]E. Regalado-Pérez, Martín G. Reyes-Banda, X. Mathew, Influence of oxygen concentration in the $\mathrm{CdCl}_{2}$ treatment process on the photovoltaic properties of $\mathrm{CdTe} / \mathrm{CdS}$ solar cells, Thin Solid Films 582 (2015) 134-138.

[19]R. Triboulet, P. Siffert (Eds.), CdTe and Related Compounds; Physics, Defects, Hetero- and Nano-structures, Crystal Growth, Surfaces and Applications, Elsevier, 2009.

[20] M. Shen, J. Zhang, L. Wang, J. Min, L. Wang, X. Liang, J. Huang, K. Tang, W. Liang, H. Meng, Investigation on the surface treatments of CdMnTe single crystals, Mat. Sci. Semicon. Proc. 31 (2015) 536-542.

[21]H. Jun-feng, X.Liu, C. Li-mei, J. Hamon, M.P. Besland, Investigation of oxide layer on CdTe film surface and its effect on the device performance, Mat. Sci. Semicon. Proc. 40 (2015) 402406.

[22] K.H. Kim, V. Carcelén, A.E. Bolotnikov, G.S. Camarda, R. Gul, A. Hossain, G. Yang, Y. Cui, R.B. James, Effective Surface Passivation of CdMnTe Materials, J. Electron. Mater. 39 (2010) 1015-1018.

[23] J F. Watts, J. Wolstenholme, An Introduction to Surface Analysis by XPS and AES, Wiley, (2003).

[24] S. S. Choi, G. Lucovsky, Native oxide formation on CdTe, J. Vac. Sci. Technol. B 6 (1988) 1198-1203.

[25]C. van der Marel, M. Yildirim, H. R. Stapert, Multilayer approach to the quantitative analysis of $\mathrm{x}$-ray photoelectron spectroscopy results: Applications to ultrathin $\mathrm{SiO}_{2}$ on $\mathrm{Si}$ and to selfassembled monolayers on gold, J. Vac. Sci. Technol. A 23 (2005) 1456-1470.

[26]B. Ravel and M. Newville, ATHENA, ARTEMIS, HEPHAESTUS: data analysis for X-ray absorption spectroscopy using IFEFFIT, J. Synchrotron Rad. 12 (2005) 537-541.

[27]I. Radisavljević, N. Ivanović, N. Novaković, N. Romčević, M. Mitrić, V. Andrić, and H.-E. Mahnke, Structural aspects of changes induced in PbTe by doping with Mn, In and Ga, J. Mater. Sci. 48 (2013) 8084-8100. 
[28]I. Horcas, R. Fernandez, J.M. Gomez-Rodriguez, J. Colchero, J. Gomez-Herrero and A. M. Baro, WSXM: A software for scanning probe microscopy and a tool for nanotechnology, Rev. Sci. Instrum. 78 (2007) 013705-8.

[29] O.M.N.D. Teodoro, J.M.A.C. Silva, and A.M.C. Moutinho, Multitechnique surface analysis system: apparatus description, Vacuum 46 (1995) 1205-1209.

[30] J.F. Ziegler, M.D. Ziegler, J. P. Biersack, SRIM - The stopping and range of ions in matter (2010), Nucl. Instrum. Meth. B 268 (2010) 1818-1823.

[31]C.D. Wagner, A.V. Naumkin, A. Kraut-Vass, J.W. Allison, C.J. Powell, J.R. Jr. Rumble, NIST Standard Reference Database 20, Version 4.1 (web version), www.srdata/nist.gov/xps/ (last accessed on June $23^{\text {rd }}$ 2018.).

[32]B.R. Strohmeier, An ESCA Method for Determining the Oxide Thickness on Aluminum Alloys, Surf. Interface Anal. 15 (1990) 51-56.

[33] M. R. Alexander, G. E. Thompson, X. Zhou, G. Beamson, N. Fairley, Quantification of oxide film thickness at the surface of aluminum using XPS, Surf. Interface Anal. 34 (2002) 485-489.

[34]T.C. Lin, G. Seshadri, J.A. Kelber, A consistent method for quantitative XPS peak analysis of thin oxide films on clean polycrystalline iron surfaces, Appl. Surf. Sci. 119 (1997) 83-92.

[35] M.P. Seah, S.J. Spencer, Ultrathin $\mathrm{SiO}_{2}$ on Si II. Issues in quantification of the oxide thickness, Surf. Interface Anal. 33 (2002) 640-652.

[36] A. Jablonski, J. Zemek, Overlayer thickness determination by XPS using the multiline approach, Surf. Interface Anal. 41 (2009) 193-204.

[37]L.T. Weng, G. Vereecke, M.J. Genet, P. Bertrand, W.E.E. Stone, X.P.S. Quantitative. I. Part, Experimental determination of the relative analyser transmission function of two different spectrometers - a critical assessment of various methods, parameters involved and errors introduced, Surf. Interface Anal. 20 (1993) 179-192.

[38] W.S.M. Werner, Electron transport in solids for quantitative surface analysis, Surf. Interface Anal. 31 (2001) 141-176.

[39]C.J. Powell, A. Jablonski, Electron effective attenuation lengths for applications in Auger electron spectroscopy and x-ray photoelectron spectroscopy, Surf. Interface Anal. 33 (2002) 211-229.

[40] A. Jablonski, C.J. Powell, The electron attenuation length revisited, Surf. Sci. Rep. 47 (2002) 33-91.

[41]C.J. Powell and A. Jablonski, NIST Effective-Attenuation-Length Database, Version 1.3, SRD 82, National Institute of Standards and Technology, Gaithersburg, MD, 2011. 
[42] C.J. Powell, A. Jablonski, Progress in quantitative surface analysis by X-ray photoelectron spectroscopy: Current status and perspectives, J. Electron Spectrosc. 178-179 (2010) 331-346.

[43] S. Kuźmiński, K. Pater, Surface states on the $\mathrm{Cd}_{1-\mathrm{x}} \mathrm{Fe}_{\mathrm{x}} \mathrm{Te}$ surfaces, Vacuum 63 (2001) 219 222.

[44]N. Bundaleski, I Radisavljević, J.Trigueiro, A. Tolstogouzov, Z. Rakočević, M. Medić, O.M.N.D.Teodoro, N. Romčević, N. Ivanović, Surface composition of $\mathrm{Cd}_{1-\mathrm{x}} \mathrm{Fe}(\mathrm{Mn})_{\mathrm{x}} \mathrm{Te}_{1-\mathrm{y}} \mathrm{Se}_{\mathrm{y}}$ systems exposed to air, Mat. Chem. Phys. 189 (2017) 35-43.

[45]B.J. Kowalski, B.A. Orłowski, J. Ghijsen, XPS study of CdTe(110) surface oxidation process, Surf. Sci. 412/413 (1998) 544-554.

[46] The UK Surface Analysis Forum, http://www.uksaf.org/ (last accessed on January $12^{\text {th }} 2018$.).

[47]H. El Maliki, J.C. Bernède, S. Marsillac, J. Pinel, X. Castel, J. Pouzet, Study of the influence of annealing on the properties of CBD-CdS thin films, Appl. Surf. Sci. 205 (2003) 65-79.

[48] J.F. Moulder, W.F. Stickle, P.E. Sobol, K.D. Bomben, Handbook of X-ray Photoelectron Spectroscopy, Perkin-Elmer Corp., 1992.

[49] J. Riga, J.J. Verbist, P. Josseaux, A. Kirsch-de Mesmaeker, Correlation between CdS photoanodic behaviour and electrode chemical modifications: An X-ray photoelectron spectroscopic study, Surf. Interface Anal. 7 (1985) 163-168.

[50]P. Bartolo-Peréz, R. Castro-Rodríguez, F. Caballero-Briones, W. Cauich, J.L. Peña, M.H. Farias, X-Ray photoelectron spectroscopy study of CdTe oxide films grown by rf sputtering with an $\mathrm{Ar}-\mathrm{NH}_{3}$ plasma, Surf. Coat. Technol. 155 (2002) 16-20.

[51]R. Castro-Rodríguez, A. Iribarren, P. Bartolo-Peréz, J.L. Peña, Obtaining of polycrystalline $\mathrm{CdTeO}_{3}$ by reactive pulse laser deposition, Thin Solid Films 484 (2005) 100-103.

[52]G. Beamson, D. Briggs, High Resolution XPS of Organic Polymers - The Scienta ESCA300 Database, Wiley Interscience, 1992.

[53] A. Roche, H. Montes, J. Brissot, M. Romand, P. Josseaux, A.Kirsch De Mesmaeker, Photoanodic behaviour of thin CdS films: Surface chemical modifications analyzed by XRFS, LEEIXS, and XPS, Applications of Surface Science 21 (1985) 12-28.

[54]D.A. Duncan, J.M. Kephart, K. Horsley, M. Blum, M. Mezher, L. Weinhardt, M. Häming, R.G. Wilks, T. Hofmann, W. Yang, M. Bär, W.S. Sampath, C. Heske, Characterization of Sulfur Bonding in CdS:O Buffer Layers for CdTe based Thin-Film Solar Cells, ACS Appl. Mater. Interfaces, 7 (2015) 16382-16386.

[55] V. Tomashyk, P. Feychuk, L. Shcherbak, Ternary Alloys Based on II-VI Semiconductor Compounds, Taylor \& Francis, 2014. 
[56] S. Tanuma, C. J. Powell, D. R. Penn, Calculations of electron inelastic mean free paths, V. Data for 14 organic compounds over the 50-2000 eV range, Surf. Interface Anal. 21 (1994) $165-176$.

[57] M.P. Seah, I.S. Gilmore, Quantitative AES. VIII: Analysis of auger electron intensities from elemental data in a digital auger database, Surf. Interface Anal. 26 (1998) 908-929.

[58] J.H. Scofield, Hartree-Slater subshell photoionization cross-sections at 1254 and 1487 eV, J. Electron Spectrosc. 8 (1976) 129-137.

[59] J.J. Yeh, I. Lindau, Atomic subshell photoionization cross sections and asymmetry parameters: $1 \leq \mathrm{Z} \leq 103$, Atom. Data Nucl. Data 32 (1985) 1-155.

[60] M. Proença, J. Borges, M.S. Rodrigues, R.P. Domingues, J.P. Dias, J. Trigueiro, N. Bundaleski, O.M.N.D. Teodoro, F. Vaz, Developmentof Au/CuO nanoplasmonic thin films for sensing applications, Surf. Coat. Tech. 343 (2018) 178-185.

[61]D. Levi, D. Albin, D. King, Influence of surface composition on back-contact performance in CdTe/CdS PV devices, Prog. Photovolt: Res. Appl. 8 (2000) 591-602.

[62]F.F. Abraham, C.R. Brundle, Surface segregation in binary solid solutions: A theoretical and experimental perspective, J. Vac. Sci. Technol. 18 (1981) 506-519.

[63] S. Adachi, Properties of Group-IV, III-V and II-VI Semiconductors, John Wiley \& Sons Ltd, Chichester, 2005.

[64]C. S. Fadley, R. J. Baird, W. Siekhaus, T. Novakov, S. Å. L. Bergström, Surface analysis and angular distributions in X-ray photoelectron spectroscopy, J. Electron Spectrosc. 4 (1974) 93137.

[65] M. K. Herndon, A. Gupta, V. Kaydanov, R. T. Collins, Evidence for grain-boundary-assisted diffusion of sulfur in polycrystalline CdS/CdTe heterojunctions, Appl. Phys. Lett. 75 (1999) 3503-3505. 